\title{
An action plan to address the rising burden of colorectal cancer in younger adults
}

\author{
Jan T Lowery*,1 (iD), Thomas K Weber ${ }^{\ddagger}{ }^{2}$, Dennis J Ahnen ${ }^{3}$, Paul C Schroy $\mathrm{II}^{4}$, Caleb L \\ Levell $^{5}$ \& Robert A Smith ${ }^{5}$ \\ ${ }^{1}$ Center for Personalized Medicine, University of Colorado, Aurora, CO 80045, USA \\ ${ }^{2}$ Northwell Health, Professor of Surgery, Donald \& Barbara Zucker School of Medicine at Hofstra/Northwell, New York, NY 10028, \\ USA \\ ${ }^{3}$ Gastroenterology of the Rockies, University of Colorado School of Medicine \& Director of Genetics Program, Aurora, CO 80045, \\ USA \\ ${ }^{4}$ Boston University School of Medicine, Section of Gastroenterology, Boston, MA 02118, USA \\ ${ }^{5}$ American Cancer Society, Atlanta, GA 30303, USA \\ *Author for correspondence: jan.lowery@cuanschutz.edu \\ ‡TK Weber is deceased
}

\begin{abstract}
Aim: The National Colorectal Cancer Roundtable convened a national Summit to discuss the causes of early-onset colorectal cancer and clinical challenges to mitigating burden of this disease. Materials \& methods: Information presented was synthesized through scientific consensus building to determine priorities for new research and practice change. Results: Research priorities include evaluating role of novel risk factors, understanding natural history and identifying ways to implement evidenced-based practices for identifying and managing at-risk persons. Practice change should focus on adoption of guidelines for collecting family history, screening in young adults at risk, provider and population awareness about risk and symptoms, and universal tumor testing. Conclusion: Successful implementation of strategies to address research and practice change will require collaboration from multiple partners.
\end{abstract}

First draft submitted: 11 March 2020; Accepted for publication: 5 June 2020; Published online: 19 October 2020

Keywords: action plan • causation • early-onset colorectal cancer $\bullet$ family history $\bullet$ hereditary cancer $\bullet$ prevention

Over 140,000 persons in the USA will be diagnosed with colorectal cancer (CRC) this year, and as many as one in seven of these individuals will be under the age of 50 [1,2]. Despite decreasing incidence of CRC overall, in the past few decades, incidence has been steadily increasing in younger adults - especially for rectal cancer [3,4]. Mortality rates have also risen in the past decade for younger, white adults, in contrast to significant reductions in incidence and mortality for older age groups.

The cause of the recent rise in early-onset CRC (EOCRC), defined herein as CRC diagnosed under age 50, is largely unexplained. There are likely multiple causes including genetic predisposition and environmental exposures, though it remains unknown as to what extent these factors explain the recent increase in EOCRC. Because of the early age of diagnosis and relatively poor prognosis, EOCRC contributes significantly to the total years of life lost from CRC [5]. CRC in younger adults is typically discovered at later stages [1,6-8], which is attributed to a combination of factors including poor identification of young adults at increased risk for CRC, low adherence to screening in at-risk young adults, delayed recognition of clinical symptoms and potentially biological differences in their tumors [6,9-13]. Given the uncertainty around its cause and missed opportunities for prevention and early detection with screening, the rise in CRC in younger adults is both a cause of great concern and a call to action.

To address this growing public health problem the National Colorectal Cancer Roundtable (NCCRT; a CRC and American Cancer Society Collaboration [both GA, USA]) convened a Summit in November 2017 with key thought leaders and national stakeholders representing diverse perspectives from academia, clinical practice, public health, clinical genetics, nonprofits and federal funding agencies. The purpose of the Summit was to review what is known about the causes of EOCRC and to assess challenges and opportunities for reducing risk and improving

Future Medicine 
outcomes for EOCRC in the USA that would inform an action plan for NCCRT and allied partners for reducing the burden of EOCRC.

\section{Methods}

\section{Summit participants}

Participants and stakeholders were chosen based on their expertise, past and on-going work in the area of EOCRC and contributions to the published literature. The purpose of the meeting was to assess how the NCCRT and its member organizations, including those representing clinical practitioners, researchers and advocacy groups, could most effectively align to address the issue; thus, it was important to invite a faculty with broad epidemiological, clinical and public health expertise. The participant list and the potential speakers were suggested by the NCCRT Chair and Steering Committee, the leadership of the Family History and Early Age Onset Colorectal Cancer Task Group of the NCCRT, the American Cancer Society (ACS) staff, with additional advice from invited speakers and event sponsors including the Colon Cancer Challenge Foundation (NY, USA), the National Cancer Research Alliance (CA, USA), a fund of the Entertainment Industry Foundation, and the ACS. The meeting roster and agenda are provided in the Supplementary Materials.

\section{Pre-meeting survey}

An electronic survey was sent to invited participants a month prior to the meeting to elicit perspectives on important unknowns about the causes of EOCRC, existing challenges for providers and practices in addressing EOCRC, how to improve educational resources to optimize uptake of information about EOCRC among providers, who are essential partners? and what are possible roles for national leaders in this area? The nine survey questions were open-ended; responses were compiled by the meeting organizing committee into common themes. Information gleaned from premeeting survey responses were reported back to the meeting attendees during the Summit. The purpose of the premeeting survey and report back process was to level-set knowledge in the room, focus discussion themes, identify areas of consensus or contention and further coordinate and prioritize the meeting agenda and topic areas.

\section{Meeting format}

The meeting was organized to allow for several presentations from national experts on key topic areas with followup question and answer sessions, group discussions and smaller breakout sessions. Invited speakers summarized the scientific evidence on the trends, etiology and molecular characteristics of EOCRC and highlighted important information gaps. Additional presentations discussed the current state of clinical practice around EOCRC. A portion of the meeting included addressing NCCRT resources and other ongoing activities that involved family history and the role of primary care providers. Breakout sessions elicited suggestions on the most important unanswered research questions, ideas on how to work with front-line providers to improve clinical practices and ways to engage partners as needed.

\section{Data synthesis \& action plan}

The evidence presented by panelists and key points raised during discussions were captured on power point slides, meeting notes and poster boards. The collective data were reviewed and synthesized through scientific consensus building, to determine priorities for research and practice change that would inform an action plan. The plan, included herein, is intended to be a working document that will initially guide activities of the NCCRT and affiliate members and that will serve as a call to action for researchers, clinicians, public health, policy makers and funding agencies to engage in this work.

\section{Results}

The opening session of the Summit focused on the current state of evidence on the trends, risk factors and molecular etiology of EOCRC. The evidence presented and key discussion points from this session are summarized below.

\section{What is the evidence for an increase in EOCRC?}

A recent analysis of CRC incidence and mortality in the USA demonstrates that while incidence rates have been falling in older age groups in recent decades, incidence has increased in younger generations. Since the mid-1990s, 
the incidence of CRC has increased by 1.0-2.4\% for persons age 20-39, and by $0.5-1.3 \%$ for those age 40-54 [3]. Based on these trends, it is predicted that by 2030 the incidence rates for persons 20-34 years of age will rise by $90 \%$ for colon and 124\% for rectal cancer, and by 27 and 46\%, respectively, for persons age 35-49 [4]. An important finding from the analysis by Siegel et al. is that the rise in incidence can be attributed to a strong birth-cohort effect; in contrast to persons born between 1890 and 1950, for whom CRC incidence has been declining, persons born after 1950 have experienced a steady increase in risk that has followed these age groups over time [3]. Individuals born around 1990 have two-times the risk for colon and four-times the risk for rectal cancer when compared with those born circa 1950. Additionally, recent data have highlighted a drop in the mean age of diagnosis, from 72 in the early 2000s to 66 years in 2016, which is attributed to the increase in EOCRC [14].

It is also notable that the majority of the increase in CRCs are occurring in the distal colon and rectum; the proportion of all CRCs diagnosed in younger adults $(<55)$ that are located in the rectum has increased twofold from 14.6 to $29.2 \%$ between 1989-1990 and 2012-2013, respectively [3]. There has been a marked difference in the incidence of EOCRC by race. Notably, while incidence in Blacks has been steadily increasing since 1975 , incidence in Whites declined substantially until the early 1990s then began to rise [3]. Similar increases in EOCRC have been reported for several other countries [15-18].

\section{What is causing the increase in EOCRC?}

The increase in incidence of EOCRC suggests a change in the prevalence/intensity of, or the sensitivity to, exposures known to increase CRC risk and/or the introduction of new exposures to younger generations that may elevate risk. Conversely, decreased exposure to protective factors in early life could also play a role.

\section{Hereditary \& familial factors disproportionately contribute to EOCRC}

Early age of onset is a hallmark of hereditary cancer syndromes. There have been at least four recent studies that have performed genetic testing on tumors from young CRC patients using broad cancer gene panels. These studies suggest that hereditary syndromes may account for between 14 and 20\% of all EOCRC and their contribution is even higher in younger cohorts [19-22]. In all of these studies, some patients with EOCRC were found to have pathogenic germ-line mutations in low penetrance CRC genes or in genes that cause syndromes that do not commonly cause CRC (e.g., monoallelic MUTYH, BRCA1/2) [19]; it has therefore been argued that some of the identified mutations may not be responsible for the CRCs and that these could overestimates of the hereditary contribution to CRC.

\section{Familial CRC, not due to known hereditary causes, independently contributes to EOCRC}

Patients with a family history of CRC or advanced adenomas of the colon (advanced adenomas are those that are $>1 \mathrm{~cm}$ or have villous features or high-grade dysplasia) are at increased risk of CRC overall and EOCRC. The risk of developing CRC is approximately twofold higher among persons with one first-degree relative (FDR) with either CRC or an advanced adenoma, and the risk is even higher if the FDR is diagnosed at a younger age or there are multiple FDRs with CRC [23]. Family history of CRC and other gastrointestinal cancers has been highlighted to be a stronger risk factor in younger adults, as compared with those in middle age and older [24,25] and the age incidence curve has shifted by approximately 10 years toward the younger generation in those with a family history of CRC compared with those without [26].

Between 3 and 10\% of the population report having one or more FDRs with CRC [27]. In contrast, recent studies have demonstrated that 14-15\% of patients under 50 with nonhereditary CRC had one or more FDRs with CRC at the time they were diagnosed [19,21]. It is not known what proportion of patients with early-onset, nonhereditary CRC have a family history of advanced adenomas, but since the prevalence of advanced adenomas is approximately tenfold higher than that for CRC [28], this could be a sizeable group.

Although hereditary and familial CRC both contribute substantially to the overall incidence of EOCRC, there is no direct evidence that the prevalence of hereditary cancer syndromes or familial CRC has changed in recent years. There is no convincing evidence that genetic anticipation (earlier age of onset of disease in later generations of families with certain hereditary syndromes) occurs in the hereditary CRC syndromes. It is plausible that earlier or increased exposure to environmental risk factors such as obesity, smoking or alcohol might lower the age of CRC in hereditary CRC syndromes or familial CRC, since they have been determined to increase the overall risk of CRC in these settings [29-32]. 
Table 1. Known colorectal cancer risk and protective factors: risk estimate, change in population prevalence in adults $<50$ years of age in recent decades.

\begin{tabular}{|c|c|c|}
\hline & Risk estimates & Change in prevalence \\
\hline \multicolumn{3}{|l|}{ Risk factors } \\
\hline Hereditary syndromes & $4.0+$ & NC \\
\hline Family history of CRC & $2.0+$ & NC \\
\hline Family history adenoma & $2.0+$ & UK \\
\hline Obesity & $1.2-1.5$ & 1 \\
\hline Sedentary lifestyle & 1.3 (colon) & NC \\
\hline Binge drinking & 1.6 & NC \\
\hline T2DM & $\begin{array}{l}1.4 \text { (colon) } \\
1.2 \text { (rectal) }\end{array}$ & 1 \\
\hline Smoking & 1.2 & $\mathrm{D}$ \\
\hline Processed meat & 1.2 & 1 \\
\hline Crohn's disease & 2.6 & NC \\
\hline Ulcerative colitis & $1.9-2.8$ & NC \\
\hline \multicolumn{3}{|l|}{ Protective factors } \\
\hline Aspirin use & 0.3 & D \\
\hline Diet (fruit/vegetables) & 0.9 & UK \\
\hline
\end{tabular}

\section{The contribution of environmental \& lifestyle risk factors to EOCRC is largely unknown}

It is likely that environmental causes of EOCRC are multiple and include some or all of those factors known to be associated with increased or decreased CRC risk. Important nonhereditary risk factors for CRC include obesity, diet (high in red and processed meat, low in fruits and vegetables), sedentary behavior, alcohol, smoking and Type 2 diabetes mellitus (T2DM) (Table 1) [33-36]. It is estimated that these lifestyle factors may explain up to $70 \%$ of CRC in older adults [34,37].

There are relatively few studies to identify risk factors for EOCRC specifically. Case-control studies suggest the possibility that heavy alcohol consumption, diets high in processed meat and T2DM, at least in men, are associated with a modest (1.4 to twofold) increased risk of EOCRC $[35,40]$ and that diets high in vegetables, folate, $\beta$-carotene and vitamin E may be associated with a modestly decreased EOCRC risk [35]. Analysis of the Nurse's Health Cohort Study demonstrated that being overweight or obese increased EOCRC risk in women by 37 and $93 \%$, respectively; both early weight (at age 18) and weight gain (after age 18) contributed to this risk [38].

Risk factors for which prevalence of exposure has changed in younger age groups in recent decades may be candidates for contributing to the rise in EOCRC. The prevalence of obesity, T2DM and processed meat consumption among the US adults under 50 has increased in recent decades, whereas smoking prevalence has decreased. Physical activity levels and binge drinking in younger age groups have remained relatively stable (Table 1) [39-44]. Aspirin use, which decreases CRC risk by about 35\% [45], is less prevalent in younger adults now than it was previously [46,47]. Following the US FDA (MA, USA) warning of the possible association between aspirin use and Reyes syndrome in the 1980s, there was a decline in aspirin use in children, followed by a significant fall in the incidence of Reyes syndrome [48].

Co-morbidities such as Crohn's disease and ulcerative colitis increase risk for CRC by two- to fivefold, but the absolute prevalence of these conditions in younger populations is low and has not changed over the past several decades [49]. Furthermore, the cancer risk associated with inflammatory bowel disease has been decreasing in the last 20 years [50].

\section{The role of screening is likely to be minimal}

It has been speculated that the rise in EOCRC may be explained by increased screening in younger adults, resulting in lead-time bias, without a real change in true CRC burden in younger generations [51]. However, while screening may explain some fraction of the increase, it is likely to be small and limited to the 40-49 year-old age group. Several indicators challenge a strong screening effect. Importantly, the greatest percent increase in incidence in 
Table 2. Potential novel risk factors and new hypotheses for early-onset colorectal cancer.

\begin{tabular}{llll}
\hline Exposure/risk factor & Genetics & Timing of exposure & Cancer site \\
\hline Antibiotic use & Lower penetrant mutations & In utero & Colon \\
Food additives & Epigenetic alterations & Early childhood & - Distal vs proximal \\
Gut microbiome & Gene-environment interactions & Adolescence & Rectum \\
Vaccines & & Teens & \\
Birth weight & & Early adult & \\
Pesticides & & \\
Insulin resistance & & \\
HPV & & \\
Helicobacter pylori & & \\
Sleep patterns & & \\
Recreational drug use & & \\
New smoking products & & \\
Decreased exposure to aspirin & &
\end{tabular}

CRC in recent decades has been in the youngest age groups (20-29) for whom screening is least likely. In addition, the majority of the increase in CRC has been for late stage cancers, as opposed to localized or early-stage cancers that are typically detected through earlier screening [3]. Furthermore, if rising incidence in adults under the age of 50 were attributable to a lead-time effect associated with screening, then CRC mortality rates would be dropping earlier than expected after the onset of guideline recommended screening. However, CRC mortality rates have been increasing for persons aged 50-54 [3]. A recent study suggests that increases in colonoscopy rates among adults age 40-54 do not accurately align with increased incidence patterns in this age group [52].

\section{The molecular pathogenesis for nonhereditary, EOCRC is not well understood}

The relatively recent change in incidence of EOCRC suggests that the cause may be due to an interaction between environmental factors (new and/or those for which prevalence has changed) and predisposing CRC genes, including both high and low penetrant genes. The molecular pathway for Lynch syndrome has been well characterized and involves the loss of mismatch repair (MMR) proteins (MLH1, MSH2, MSH6, PMS2, EPCAM) and microsatellite instability (MSI) detected by PCR. These markers are present in 10-20\% of EOCRC and are most commonly an indicator of Lynch syndrome in the young (whereas somatic hypermethylation of $M L H 1$ is the most common cause of MSI in late-onset CRC) [53-56]. There are no comparably sensitive molecular markers for sporadic EOCRC but certain molecular features are differentially represented in this group. Compared with late-onset CRC, EOCRCs tend to be microsatellite and chromosome stable, negative for mutations in the APC tumor-suppressor gene, and less likely to have BRAF mutations or the CPG island methylator phenotype [57-59].

Another hypothesis involves the emerging role of epigenetics. There is some evidence that hypomethylation, specifically in LINE-1 (long-interspersed nuclear elements) may be associated with EOCRC. LINE-1 sequences are repetitive sequences of around 6000 base pairs. These elements constitute $17 \%$ of our genome and are normally silenced via methylation; if LINE-1 sequences are turned on by hypomethylation, it could lead to increased expression of tumor-promoting genes. One study, by Antelo et al. [60] demonstrated that LINE-1 hypomethylation in early-onset tumors was significantly higher than in tumors of older adults and those with Lynch syndrome and, survival related to these tumors was poor, suggesting that these tumors may be inherently different. There is no current evidence that genome-wide hypermethylation is related to EOCRC [60,61]. This is of interest because hypermethylation is a marker for inflammation, which is one proposed mechanism by which obesity, inactivity and dietary factors may affect CRC risk [62].

\section{New hypotheses are needed}

Collectively, the limits of the evidence presented signals the need to better understand the impact that known CRC risk factors have on the escalating occurrence of CRC in younger age groups, and to explore the role of novel risk factors and new hypotheses to assess causal pathways. Several potential risk factors were put forth (Table 2) antibiotic use in childhood and changes in the food supply (more additives and processed foods), which may affect the colonic microbiome were among those raised. It was noted that the increase in EOCRC has been largely in the rectosigmoid, thus it was stressed that stratification of risk factors by cancer site (colon vs rectosigmoid) would be important. Furthermore, it would be important to evaluate whether the proportionate increase in rectal tumors in younger adults is also occurring in persons over 50 . Timing of exposure was also discussed, emphasizing the need 
to explore the impact of early exposures (e.g., in utero and early childhood) and the interaction between various exposures and developmental timelines.

What are the current challenges to prevention \& management of EOCRC in clinical practice? Discussions on this topic focused on three key areas: identification of persons and family members at risk for EOCRC, screening adherence in younger adults at risk and early recognition of symptoms.

\section{Identification of young adults at increased risk for CRC due to hereditary or familial factors is inadequate}

Hereditary and familial CRC syndromes are important risk factors for CRC and, as noted above, a substantial proportion of patients with EOCRC have such syndromes: approximately $14-20 \%$ have a known hereditary cancer syndrome and another 14-15\% reported having an affected FDR with CRC at the time of diagnosis in the absence of a hereditary syndrome $[19,21]$. All of the US CRC screening guidelines recommend starting screening at age 40 (or earlier if the FDR had EOCRC) in individuals with an FDR with of CRC or advanced adenomas [63,64]. Screening should start even earlier in those with a hereditary CRC syndrome, for example, in Lynch syndrome guidelines recommend starting colonoscopy screening at age 25 or 10 years earlier than the earliest cancer in the family whichever is earlier [63]. Currently, however, only a minority of young adults at increased risk for hereditary or familial CRC are identified in clinical practice $[65,66]$. Although one cannot know for certain how many early-onset cancers could be prevented through family history assessment, it is conceivable that if these individuals had been identified and properly referred for earlier screening, a significant proportion of these cancers could have been prevented or detected at an earlier stage.

Primary care clinicians play a critical role in collecting and acting on cancer family history. However, knowledge among providers surrounding hereditary CRC risk and appropriate screening guidelines is limited and collection of family history in both primary care and specialty practice remains sub-optimal $[10,11,67]$. Earlier studies suggest that less than half of patients under the age of 50 are asked about their family history of CRC, and most do not have sufficient family history information documented in their medical record to adequately inform risk and medical management [10,67-69]. Furthermore, only a minority of patients with significant family histories are referred for genetic risk assessment and a large proportion of these patients (40\%) do not follow through with the referral $[11,67]$.

Although collecting adequate family history is essential, it was noted that family history alone cannot identify all young adults with a hereditary CRC syndrome. In the three recent series reporting panel testing, only 25-51\% of patients with EOCRC with an identifiable mutation for hereditary cancer reported a positive family history of CRC [19-21]. Thus, in addition to improvements in family history collection and use for earlier screening, other strategies are needed to optimize identification of young adults at risk.

\section{Adoption of universal tumor testing for Lynch syndrome is slow}

Testing of all CRCs for DNA MMR deficiency is widely recommended in the USA utilizing either a PCR assessment of MSI or immunohistochemical evaluation of the expression of the four DNA MMR proteins [70]. However, the most recent nationwide assessment (in 2012) demonstrated that only $71 \%$ of NCI-designated cancer centers, $36 \%$ of Commission on Cancer $(\mathrm{CoC})$ accredited hospitals and $15 \%$ of non-CoC accredited community hospital programs have implemented universal tumor screening [71]; approximately $80 \%$ of cancer patients in the USA are treated at these hospitals [72,73]. Nonetheless, a recent analysis of data from the National Cancer Database for 2010-2012 determined that only $43.1 \%$ of young onset cases ( $<50$ years) had been tested [74], and a second study using data from the Louisiana central cancer registry highlighted that only $23 \%$ of tumors from patients diagnosed with CRC under age 50 had undergone MSI and/or immunohistochemistry testing [75]. Limited adoption of recommendations for CRC tumor testing is a missed opportunity to identify patients at risk for hereditary cancer and their family members, who may be at risk for future cancers. A national survey of gastroenterologists observed that cost, unfamiliarity with guidelines and interpretation of results, and low availability of genetic counseling services were viewed as important barriers to ordering tumor testing [76]. Efforts to increase adoption must address both provider and systems-level barriers.

\section{CRC screening adherence among high-risk persons under age 50 is lagging}

Persons under age 50 are recommended to begin screening early (at age 40 or younger) if they have a FDR that has been diagnosed with CRC or an advanced adenoma [64]. A meta-analysis [77] estimated that only approximately $30 \%$ of persons with a family history of CRC are adherent with current screening guidelines and that the rate 
of adherence in the 40-49 age group is even lower, though this analysis includes data from countries that have much lower screening rates than the USA. Although screening rates for persons with a family history of CRC have increased overall in the USA, in the last decade (from 25 to 66\%), rates for those aged 40-49 continue to lag behind (38\%) [12].

Numerous reasons for non-adherence have been identified including not having a provider recommendation, lack of symptoms and anticipation of pain from sigmoidoscopy or colonoscopy [78,79]. Provider and systems-level barriers to screening in high-risk groups include a lack of availability of educational materials to properly identify and refer high-risk patients and the lack of systematic means for collecting family history in clinical practice [80].

In 2018, the ACS changed their recommended age of screening initiation for average risk persons from 50 to 45 [5]. If the ACS guidelines are widely adopted, it may have a substantial impact on incidence and stage of diagnosis among adults age 45-49. This age group accounts for almost half of all CRCs under age 50, over 5\% of all CRC deaths and about $10 \%$ of all person life-years lost to CRC, and both the CRC incidence and mortality continue to increase in this group. The guideline change by the ACS was based largely on the evidence of a birth cohort effect resulting in rising incidence in younger ages, and on results from a recent simulation model conducted by the Cancer Intervention and Surveillance Modeling Network (CISNET; MA, USA) that incorporated estimates of current incidence and mortality data; previous models had used incidence and mortality data from 1975 to 1979 that preceded the significant increase in EOCRC. The goal was to determine the age and frequency of screening that would maximize benefit (measured in life years gained) and minimize harm (risks from colonoscopy). Results suggest that starting colonoscopy at age 45 and screening every 10 years would be the optimal screening regimen [81]. Screening from age 45 to 75 , rather than at age 50-75, using colonoscopy every 10 years as the screening strategy, resulted in approximately a $6 \%$ increase in years of life gained at a burden of a $17 \%$ increase in the number of colonoscopies needed; similarly annual fecal immunochemical test screening at age 45-75 rather than age 50-75 resulted in an estimated $7 \%$ increase in years of life gained at a burden of a $12 \%$ increase in the number of colonoscopies needed [81].

An important limitation to the CISNET model is that the information on the rate of adenoma occurrence and progression was based on data from older populations [81]. Similar data from younger cohorts are needed to better understand the natural history of EOCRC and to inform future simulation models.

\section{Time to diagnosis of $C R C$ is much longer for younger adults}

The vast majority of persons under 50 have symptoms at the time of diagnosis [8]. Common symptoms include blood in the stool, persistent diarrhea, constipation or abdominal pain. There are other common causes of these symptoms in younger persons, thus, these symptoms are often not recognized by patients or providers as early signs of CRC. For example, rectal bleeding in younger persons is often presumed to be due to hemorrhoids $[8,68]$. The average time to diagnosis of CRC for persons under age 50 is significantly longer than that for older persons [13] with one study reporting a difference of up to 6 months [82]. While it is not clear if the delay in diagnosis is a major cause of the later stage at diagnosis of EOCRC [13], it highlights the need for improvement in the earliest possible diagnosis of CRC in younger adults. Studies cite that the delay is typically due to a combination of patients delaying communication with their providers about their symptoms, and providers not recommending appropriate and timely workup $[8,83,84]$. Increased awareness and education about the signs and symptoms of CRC and the new reality of CRC risk in young adults must be targeted to both the general public and providers.

\section{An action plan for reducing burden of EOCRC}

The information presented and discussed at the Summit provide the basis of an action plan that has three key objectives: to accelerate research to address unanswered questions about the causes of the increase of EOCRC, the efficacy of screening in younger populations and best practices for identifying at-risk patients in clinical settings; to increase adoption of evidenced-based practices to identify and manage younger adults at risk for CRC and facilitate early diagnosis; and to solidify commitment from engaged partners that will be essential for moving this plan into action.

For each objective, the group identified priorities for what we need to know or do, strategies for addressing these priorities, the resources needed and key partners that should be engaged to move this work forward (Tables 3-5). 
Table 3. Objective 1: accelerate research to address unanswered questions about early-onset colorectal cancer.

\begin{tabular}{|c|c|c|c|}
\hline Priorities: What do we need to know/do? & Strategies: How can we do this? & $\begin{array}{l}\text { What resources are available or } \\
\text { needed? }\end{array}$ & Who needs to be engaged? \\
\hline $\begin{array}{l}\text { What is the cause of the rising incidence of } \\
\text { EOCRC? } \\
\text { - What is role of known RFs? } \\
\text { - What is role of novel /proposed RF? } \\
\text { - Do RF differ by site, i.e., colon vs rectum? } \\
\text { - Are there vulnerable times of exposure } \\
\text { related to risk for EOCRC? } \\
\text { - How has prevalence of RFs changed? } \\
\text { - What if any is the impact of changes in } \\
\text { clinical practice on EOCRC } \\
\text { (e.g., medications, screening, colonoscopy } \\
\text { use) } \\
\text { - Is EOCRC molecularly different than CRC } \\
\text { in older adults? If so, what does it tell us } \\
\text { about causation? } \\
\text { - What is the role of epigenetics? }\end{array}$ & $\begin{array}{l}\text { - Conduct prospective } \\
\text { case-control studies nested } \\
\text { within existing cohort or large } \\
\text { health system with EMR } \\
\text { - Conduct retrospective } \\
\text { case-control studies } \\
\text { - Convene group of top } \\
\text { epidemiologists to design study } \\
\text { and write proposal }\end{array}$ & $\begin{array}{l}\text { Available: } \\
\text { - Existing cohorts (CCFRC, CPS-3, } \\
\text { ARIC-CA, Millennium Cohort Study) } \\
\text { - Other cohorts; Nurses' Health Study, } \\
\text { Physicians Study } \\
\text { - Childhood cohorts linked with cancer } \\
\text { registries (Natl longitudinal survey of } \\
\text { youth, } 1970 \text { British Cohort Study, } \\
\text { Greater Boston Otitis Media Study) } \\
\text { Needed: } \\
\text { - New funding } \\
\text { Access to EHR data from health systems }\end{array}$ & $\begin{array}{l}\text { - Academic partners } \\
\text { - Integrated healthcare systems } \\
\text { like Kaiser or VA or large hospital } \\
\text { groups with EMRs } \\
\text { - Center for Microbiome } \\
\text { Research } \\
\text { - Funding agencies: NCI, ACS }\end{array}$ \\
\hline $\begin{array}{l}\text { What is the natural history of EOCRC? } \\
\text { - What is the prevalence of adenomas in } \\
\text { younger adults? } \\
\text { - What is rate of progression from } \\
\text { adenoma to carcinoma in younger adults? } \\
\text { - What is the screening regimen that will } \\
\text { optimize reduction in incidence and } \\
\text { mortality of EOCRC? }\end{array}$ & $\begin{array}{l}\text { - Collect colonoscopy data from } \\
\text { screened individuals of all ages } \\
\text { and indications for screening } \\
\text { - Data modeling } \\
\text { - Review existing colonoscopy } \\
\text { databases } \\
\text { - Compare average age of } \\
\text { adenoma, advanced adenomas } \\
\text { and CRC in cohort of first } \\
\text { colonoscopy in } 45-49 \text { years olds }\end{array}$ & $\begin{array}{l}\text { Available: } \\
\text { - GIQulC, the New Hampshire } \\
\text { Colonoscopy Registry and other } \\
\text { endoscopic databases } \\
\text { - The German colonoscopy screening } \\
\text { database } \\
\text { Needed: } \\
\text { - } 45-49 \text { years-old screening registry }\end{array}$ & $\begin{array}{l}\text { - Gastroenterology groups } \\
\text { - CISNET } \\
\text { - Other modeling groups }\end{array}$ \\
\hline $\begin{array}{l}\text { What are best practices for implementing } \\
\text { current recommendations for identifying } \\
\text { and managing EOCRC? }\end{array}$ & $\begin{array}{l}\text { - Randomized-controlled trials } \\
\text { or pragmatic trials within clinic } \\
\text { or healthcare systems } \\
\text { - Learn from on-going studies }\end{array}$ & $\begin{array}{l}\text { Available: } \\
\text { - Moonshot request for applications } \\
\text { - CDC Public health genomics states } \\
\text { - Tumor registries } \\
\text { Needed: } \\
\text { - Common evaluation metrics }\end{array}$ & $\begin{array}{l}\text { - Healthcare systems } \\
\text { - Providers: oncology, primary } \\
\text { care, genetic counselors } \\
\text { - Public health } \\
\text { - Tumor registry }\end{array}$ \\
\hline $\begin{array}{l}\text { What research is on-going that may answer } \\
\text { some of these questions? }\end{array}$ & $\begin{array}{l}\text { - Search } \mathrm{NCl}, \mathrm{NIH}, \mathrm{ACS} \text {-funded } \\
\text { grants } \\
\text { - Survey national and } \\
\text { international experts/groups } \\
\text { involved in this work }\end{array}$ & $\begin{array}{l}\text { Available: } \\
\text { - Search databases for } \mathrm{NCI}, \mathrm{NIH}, \mathrm{ACS} \\
\text { Needed: } \\
\text { - Intern/fellows/staff to reach out to } \\
\text { investigators and collate information }\end{array}$ & $\begin{array}{l}\text { - NCl, ACS, NCCRT } \\
\text { - Patient advocacy groups } \\
\text { - Insight investigators } \\
\text { - On-going cohort investigators }\end{array}$ \\
\hline
\end{tabular}

ACS: American Cancer Society; ARIC-CA: Atherosclerosis Risk in Communities Cohort; CCFRC: Colon Cancer Family Registry Cohort; CDC: Centers for Disease Control; CISNET: Cancer Intervention and Surveillance Modeling Network; CPS-3: Cancer Prevention Study; CRC: Colorectal cancer; EOCRC: Early-onset colorectal cancer; EMR: Electronic medical record; EHR: Electronic health record; GIQulC: GI Quality Improvement Consortium; NCCRT: National Colorectal Cancer Roundtable; NCI: National Cancer Institute; NIH: National Institute of Health; RF: Risk factor; VAMC: Veterans Administration Medical Centers.

\section{Objective 1: accelerate research}

Research priorities focus on determining the contribution of both known and novel risk factors for the recent increase of EOCRC that is dominated by distal and rectal tumors and steeper among whites (Table 3). The group also emphasized the need to understand changes in the prevalence of exposures and risk factors over time in younger cohorts and how these changes align with critical points of exposure across the life course to explain the strong cohort effect observed, and potentially to account for differences in trends by race. The goal of this research agenda is to identify possible causative factors and opportunities for early intervention or risk stratification to inform prevention efforts.

Possible study designs were discussed. The idea of a large case-control study, nested within an existing cohort (e.g., the Colon Cancer Family Registry Cohort [CCFRC], Nurse's Health Study, Health Professional Follow-up Study or children's cohort studies from the 1970s) or a prospective case-control study conducted within one or more large healthcare systems with robust electronic health records was raised. Important components for such a study would include having a large and representative sample size (with ample younger adults with and without CRC), availability and careful selection of the most appropriate control groups, validated outcomes (CRC, adenomas) in the medical record or via linkage with tumor registries, and comprehensive information on the many exposures of interest (Tables $1 \& 2$ ). For either type of study design, retrospective capture of early-life exposures via electronic health records and/or personal interviews could be supplemented with prospective collection of risk factor data as 
Table 4. Objective 2: increase adoption of evidenced-based practices to identify and manage persons at risk for early-onset colorectal cancer.

\begin{tabular}{|c|c|c|c|}
\hline Priorities: What do we need to know/do? & Strategies: How can we do this? & $\begin{array}{l}\text { What resources are available or } \\
\text { needed? }\end{array}$ & Who needs to be engaged? \\
\hline \multicolumn{4}{|l|}{ Provider level } \\
\hline $\begin{array}{l}\text { Improve provider education about EOCRC } \\
\text { - Rising incidence of EOCRC } \\
\text { - Signs and symptoms of EOCRC } \\
\text { - Separate screening versus diagnostic } \\
\text { recommendations for colonoscopy }\end{array}$ & $\begin{array}{l}\text { - Disseminate Family History and } \\
\text { EOCRC Provider Toolkit } \\
\text { - Develop/disseminate CMEs } \\
\text { - Engage provider groups } \\
\text { - Engage payers in developing } \\
\text { quality measures } \\
\text { - Create educational campaigns } \\
\text { directed to providers }\end{array}$ & $\begin{array}{l}\text { Available: } \\
\text { - Family History and EOCRC } \\
\text { Provider Toolkit } \\
\text { - NCCRT and ACS education } \\
\text { resources } \\
\text { - Existing CMEs } \\
\text { Needed: } \\
\text { - New messages to alert } \\
\text { providers }\end{array}$ & $\begin{array}{l}\text { - Provider professional societies } \\
\text { - Primary care groups } \\
\text { - Medical liability/malpractice } \\
\text { insurers } \\
\text { - Payers } \\
\text { - NCCRT/Jackson Laboratories } \\
\text { - Advocacy groups } \\
\text { - Other guideline groups }\end{array}$ \\
\hline $\begin{array}{l}\text { Improve screening adherence in young adults: } \\
\text { - Lynch syndrome: age } 25 \text { or younger, annually } \\
\text { - Moderate risk due to family history: age } 40 \text { or } \\
\text { younger; every } 3-5 \text { years } \\
\text { - Population: age } 45 \text {, every } 10 \text { years }\end{array}$ & $\begin{array}{l}\text { - Integrate risk-based screening } \\
\text { messages into EMR } \\
\text { - Develop new messages to alert } \\
\text { patients and providers }\end{array}$ & $\begin{array}{l}\text { Available: } \\
\text { - Family History and EOCRC } \\
\text { Provider Tool Kit } \\
\text { - NCCRT and ACS educational } \\
\text { resources } \\
\text { Needed: } \\
\text { - Evaluation of Toolkit }\end{array}$ & $\begin{array}{l}\text { - ACS, CDC } \\
\text { - Primary care groups } \\
\text { - Screening providers } \\
\text { - Public health } \\
\text { - Advocacy groups }\end{array}$ \\
\hline \multicolumn{4}{|l|}{ Patient level } \\
\hline $\begin{array}{l}\text { Improve population awareness of } \\
\text { - The importance of family history as a risk factor } \\
\text { for CRC } \\
\text { - The recommendations for earlier screening } \\
\text { based on family history of CRC or advanced } \\
\text { adenomas } \\
\text { - The risk and symptoms of EOCRC }\end{array}$ & $\begin{array}{l}\text { - Media campaigns } \\
\text { - Social media } \\
\text { - New apps for phone/tablets }\end{array}$ & $\begin{array}{l}\text { Available: } \\
\text { - Existing campaigns } \\
\text { Needed: } \\
\text { - New messages with marketing } \\
\text { plan }\end{array}$ & $\begin{array}{l}\text { - Public health } \\
\text { - Patient advocacy groups; Fight } \\
\text { CRC, Colon Cancer Alliance; } \\
\text { Colon Cancer Challenge } \\
\text { Foundation }\end{array}$ \\
\hline Improve uptake on referrals for risk assessment & $\begin{array}{l}\text { - Utilize patient navigators } \\
\text { - Remove barriers: insurance, } \\
\text { discrimination, cost, fear } \\
\text { - Expand use of tele-counseling } \\
\text { services }\end{array}$ & $\begin{array}{l}\text { Available: } \\
\text { - Tele-counseling services } \\
\text { - Counseling via laboratories } \\
\text { Needed: } \\
\text { - Streamlined referral systems } \\
\text { - Better communication } \\
\text { between providers, patients, } \\
\text { counselors } \\
\text { - Coordinated care for high risk }\end{array}$ & $\begin{array}{l}\text { - Genetic counselors } \\
\text { - Physicians } \\
\text { - Healthcare systems } \\
\text { - Payers }\end{array}$ \\
\hline \multicolumn{4}{|l|}{ Systems level } \\
\hline $\begin{array}{l}\text { Improve collection and use of family history (CRC } \\
\text { and polyps) in primary care in younger adults to } \\
\text { inform screening and referral for risk assessment }\end{array}$ & $\begin{array}{l}\text { - Enhance EMRs; collect family } \\
\text { history of CRC and adenomas } \\
\text { and integrate provider alerts } \\
\text { - Integrate risk assessment tools } \\
\text { into practice } \\
\text { - Promote use of patient portals } \\
\text { - Develop clinical guidelines and } \\
\text { quality measures for workup of } \\
\text { common symptoms for EOCRC }\end{array}$ & $\begin{array}{l}\text { Available: } \\
\text { - Jackson Labs, NCCRT, CMEs } \\
\text { - EMR vendors willing to } \\
\text { collaborate } \\
\text { Needed: } \\
\text { - Easy-to-use, validated risk } \\
\text { assessment tools }\end{array}$ & $\begin{array}{l}\text { - Primary care providers and } \\
\text { professional organizations } \\
\text { - EMR vendors } \\
\text { - NCCRT } \\
\text { - ACS-CAN WG on EMR and } \\
\text { family history }\end{array}$ \\
\hline $\begin{array}{l}\text { Increase adoption of universal tumor testing for } \\
\text { LS and cascade screening }\end{array}$ & $\begin{array}{l}\text { - Educate health systems } \\
\text { - Include in CoC accreditation }\end{array}$ & $\begin{array}{l}\text { Available } \\
\text { - EGAPP recommendations } \\
\text { - Implementation guides } \\
\text { Needed: } \\
\text { - New incentives to adopt } \\
\text { universal tumor testing for LS } \\
\text { - Institutional commitment }\end{array}$ & $\begin{array}{l}\text { - Healthcare systems } \\
\text { - Pathology departments } \\
\text { - CoC } \\
\text { - Cancer centers } \\
\text { - ACS, CDC Office of Public } \\
\text { Health Genomics }\end{array}$ \\
\hline
\end{tabular}

ACS-CAN: American Cancer Society Cancer Action Network; CDC: Centers for Disease Control; CME: Continuing Medical Education; CoC: Commission on Cancer; CRC: Colorectal cancer; EGAPP: Evaluation of Genomic Applications in Practice; EMR: Electronic medical record; EOCRC: Early-onset colorectal cancer; LS: Lynch syndrome; NCCRT: National Colorectal Cancer Roundtable.

well as blood, urine, stool and tumor samples, which would facilitate discovery of novel molecular pathways and markers for EOCRC (genetic and epigenetic). Including individuals with both young and older age of onset would enable comparison of risk factors and molecular features of the two groups to assess if these are similar or distinct types of CRC. If there were enough cases and long enough follow-up, an advantage to the nested case-control 
Table 5. Objective 3: solidify commitment from engaged and new partners to move plan into action.

\begin{tabular}{|c|c|c|c|}
\hline $\begin{array}{l}\text { Priorities: What do we need to } \\
\text { know/do? }\end{array}$ & Strategies: How can we do this? & $\begin{array}{l}\text { What resources are available or } \\
\text { needed? }\end{array}$ & Who needs to be engaged? \\
\hline $\begin{array}{l}\text { Provide forum for on-going discussion } \\
\text { of issues related to EOCRC }\end{array}$ & $\begin{array}{l}\text { - Support and participate in the annual } \\
\text { NYC EAO-CRC Summit } \\
\text { (www.coloncancerfoundation.org) } \\
\text { - Support other advocacy group efforts } \\
\text { to address EOCRC }\end{array}$ & $\begin{array}{l}\text { Available: } \\
\text { - NCCRT infrastructure and staff } \\
\text { - Advocacy groups and staff } \\
\text { Needed: } \\
\text { - Coordination and communication } \\
\text { - Goodwill }\end{array}$ & $\begin{array}{l}\text { - NCCRT, ACS } \\
\text { - Advocacy groups }\end{array}$ \\
\hline $\begin{array}{l}\text { Publish a collaborative paper or white } \\
\text { paper with } \mathrm{NCl}, \mathrm{ACS}, \mathrm{CDC} \text { with unified } \\
\text { statement }\end{array}$ & $\begin{array}{l}\text { - Get support from entire group } \\
\text { - Recruit writing committee }\end{array}$ & $\begin{array}{l}\text { Available: } \\
\text { - NCCRT member expertise } \\
\text { - Links with } \mathrm{NCl}, \mathrm{ACS} \text { and } \mathrm{CDC} \\
\text { Needed: } \\
\text { - Resources, enthusiasm, leadership }\end{array}$ & $\begin{array}{l}\text { - } \mathrm{NCl}, \mathrm{ACS}, \mathrm{CDC} \\
\text { - Lead author(s) } \\
\text { - } \mathrm{NCCRT} \text { content experts }\end{array}$ \\
\hline $\begin{array}{l}\text { Engage healthcare systems in setting } \\
\text { national research agenda around } \\
\text { EOCRC }\end{array}$ & $\begin{array}{l}\text { - Identify champions within several } \\
\text { systems } \\
\text { - Promote implementation research; } \\
\text { identify specific opportunities }\end{array}$ & $\begin{array}{l}\text { Available: } \\
\text { - Outline of research priorities (from } \\
\text { Plan) } \\
\text { Needed: } \\
\text { - Implementation Scientists } \\
\text { - Leadership/commitment from } \\
\text { healthcare systems }\end{array}$ & $\begin{array}{l}\text { - Healthcare systems leadership } \\
\text { - Experts in EOCRC research } \\
\text { - Implementation scientists }\end{array}$ \\
\hline $\begin{array}{l}\text { Convene the leadership of the } \\
\text { professional societies (internal } \\
\text { medicine, family practice, Gl, GYN, } \\
\text { general surgery, etc.) to formulate } \\
\text { strategies to work on the problem }\end{array}$ & $\begin{array}{l}\text { - Facilitate national meeting of key } \\
\text { stakeholders } \\
\text { - Identify champions to move work } \\
\text { forward }\end{array}$ & $\begin{array}{l}\text { Available: } \\
\text { - Society membership charters and } \\
\text { rosters } \\
\text { Needed: } \\
\text { - Interest, enthusiasm, champions }\end{array}$ & $\begin{array}{l}\text { - Professional societies } \\
\text { - NCCRT } \\
\text { - Experts in quality metrics } \\
\text { - Payers }\end{array}$ \\
\hline
\end{tabular}

study within existing cohorts would be that EOCRC cases from recent years could be compared with EOCRCs from the 1980s or earlier to those occurring more recently in order to isolate factors associated with the increase in EOCRC in the last 25 years.

A second research priority is to collect new or existing data to inform models for estimating optimal screening regimens in younger adults. US sources for these data may include screening registries such as GI Quality Improvement Consortium (GIQuIC; MA, USA) or the New Hampshire Colonoscopy Registry (NH, USA) that collect data on a large number of colonoscopies performed in young adults for a variety of indications [85] but international registries might be even more robust. These datasets could provide more recent data on adenoma prevalence in young adults, with the caveat that analyses must control for the indication for the colonoscopy in individuals outside of the typical screening age.

The final priority is implementation of research that can inform best practices for improving adoption of evidenced-based guidelines into clinical settings. Examples of the goals of this type of research may include identifying new and effective strategies for systematically collecting family history to inform risk and screening, implementing evidence-based screening guidelines based on familial risk, improving referral rates and update for genetic risk assessment, and increasing adoption of universal tumor testing for hereditary CRC in hospitals and healthcare systems. This research will require collaboration and commitment from provider groups and healthcare systems that are willing to embed these evidence-based strategies into real-world clinical settings, and funding opportunities that focus on these needs and support participation from community-based, nonacademic healthcare centers.

As a first step to moving forward with a research agenda, the group proposed that conducting an environmental scan of ongoing and planned research around EOCRC would be beneficial. This exercise could determine if gaps discussed at the Summit were already being addressed, how and by whom, and it could identify opportunities for collaboration. For example, there is an on-going study within several healthcare systems in the USA that seeks to identify patient and systems-level factors that facilitate and impede adoption of universal tumor testing for Lynch syndrome [86]. A second step may involve convening a group of researchers (epidemiologists, clinicians, statisticians) to develop optimal study designs for each of the research priorities, identify needed partners (researchers, existing cohorts and healthcare systems) and possible funding mechanisms. 
Several funding opportunities relevant to research around CRC and hereditary cancer were presented at the Summit by representatives from National Cancer Institute (NCI; MA, USA) and ACS. Notably, in the past year, the NCI released several funding announcements around the Cancer Moonshot Initiative that are particularly relevant to EOCRC.

\section{Objective 2: increase adoption of existing evidenced-based practices}

The group identified several strategies for addressing challenges and missed opportunities that target providers, patients and healthcare systems (Table 4). Provider level strategies focus on the need to increase awareness of the increasing trends around EOCRC and patients who may be at risk, the importance of family history in informing risk and screening, and the early signs and symptoms of CRC. The new Family History and Early Onset CRC toolkit developed by Jackson Laboratories addresses many of these issues. Broader dissemination of this toolkit to provider groups and primary care practices across the country with an appropriate evaluation plan to assess effectiveness was identified as a key strategy. Professional societies should be engaged to play a significant role in dissemination of the toolkit or other relevant educational materials and in setting expectations and standards for providers related to adequate collection of family history, screening rates for high-risk patients and earlier recognition of worrisome symptoms and diagnosis of CRC in young patients. Working with large primary care practice groups to develop and present educational programs around these issues that provide continuing medical education (CME) credit may provide added incentives for providers to engage in these activities.

Patient-targeted strategies focus on increasing patient and population awareness about CRC as a real and emerging risk for young adults, the importance of not ignoring rectal bleeding or other symptoms because of young age, improving adherence to risk-based screening guidelines, the importance of patients knowing their family history of cancer and conveying that information to their providers, and uptake of genetic counseling and testing for those referred. The group agreed that new, simple messaging that addresses the common misperception that 'CRC only occurs in older people' is needed. Partnering with organizations with ongoing media campaigns and educational resources with well-defined dissemination platforms and broad reach (e.g., by ACS, Fight CRC [DC, USA], Colon Cancer Challenge Foundation, Colon Cancer Alliance [DC, USA] and other patient advocacy groups) may be a relatively easy and impactful start; developing new campaigns through social media could also be initiated with minimal effort and resources [85]. Increasing adherence to screening and referrals to genetic services will require a more targeted approach and a concerted effort from patients and their providers (physicians and other clinical staff, genetic counselors and patient navigators) to recognize and address barriers such as misinformation, cost, fear, transportation and insurance implications. Understanding current practices within various clinical settings and systems that have been successful in these efforts could inform next steps.

System-level approaches to improve identification of persons at risk of CRC due to family history and early symptoms include enhancing use of technology (e.g., using EMRs and patient portals to systematically collect family history; building in practice alerts to prompt further testing in symptomatic patients). These strategies will require engagement of EMR vendors and support from leadership at individual practices and healthcare systems. A second priority identified is to increase adoption of current recommendations for implementation of universal CRC testing for MMR deficiency to help identify patients with Lynch syndrome. Success in implementing these strategies may also be enhanced with support from professional organizations that define quality metrics (e.g., Centers for Medicare and Medicaid Services [CMS; MA, USA], National Quality Forum [DC, USA]), and those that set standards for provision of clinical services for cancer care and for data collection such as the CoC, American Society of Clinical Oncology (ASCO; VA, USA) and the North American Association of Central Cancer Registries (NAACCR; IL, USA). In addition, there are five states currently funded by the Centers for Disease Control (GA, USA) Office of Public Health Genomics to promote adoption of genomic applications into clinical care and public health [87]. Some of these statewide programs are working with hospitals and healthcare systems to enhance and/or begin implementation of universal tumor testing for Lynch syndrome and in some states, the state cancer registry now requires that hospitals report outcomes from tumor testing (e.g., MSI, immunohistochemistry status). Partnering with these states in these efforts may be fruitful.

\section{Objective 3: solidify commitment from partners}

The key to the successful implementation of the action plan is engagement and commitment from multiple partners. Key strategies identified for the NCCRT are to hold annual meetings with stakeholders to keep the dialogue around EOCRC at the forefront, and by supporting and promoting on-going activities of advocacy groups that have made 
this work a priority. An example is the Annual New York City EAO-CRC Summit hosted by the Colon Cancer Foundation (NY, USA). Other strategies include convening a writing committee for a white paper to address urgent needs around EOCRC, and facilitating new partnerships with professional societies, healthcare systems, payers and funders who will be essential partners in moving the research agenda forward and in addressing practice change (Table 5).

\section{Action plan timeline}

The group identified short and long-term goals. Achievable short-term goals include those that require limited resources and/or that build upon existing programs, campaigns and partnerships. Long-term goals (3-5 years) will require additional resources and time. Recent and on-going efforts that address some goals are noted.

Short-term goals:

- Promote broad adoption of the new ACS screening guidelines to begin screening at age 45

- NCCRT includes the ACS age 45 guidelines in all resources from 2018 forward

- NCCRT created CRC Screening Messaging Guidebook that targets the 45-49 age group [88]

- ACS-CAN advocates for states to update state mandates that direct screening coverage

- Conduct landscape of on-going and planned studies related to EOCRC

- $\quad$ Fight CRC workshop held in Denver, CO 2019 [89]

- Explore availability/feasibility of utilizing data sources to assess adenoma prevalence and progression in young adults

- NCCRT created Advanced Colorectal Polyp GI Brief with supporting article in American Journal of Gastroenterology [90,91]

- Develop dissemination strategy and evaluation plan for the Family History and Early Onset Provider Tool Kit developed by Jackson Laboratories

- NCCRT created strategy and presented at conferences (NYC EAO-CRC Summit 2018, NCCRT Annual Meeting); available on Jackson Lab website and the NCCRT website

- Identify champions at professional societies to establish partnerships for dissemination of the Tool Kit

- Contacts were sent the 2018 dissemination strategy representing GI, primary care, family physicians, community health centers, genetics

- Special symposium held at the 2018 EAO-CRC Summit hosted by the Colorectal Cancer Challenge Foundation

- Identify opportunities for partnering with advocacy groups in population-based media campaigns and educational initiatives

- Convene groups of researchers to discuss and facilitate development of new research studies around etiology and implementation science

- Fight CRC workshop held in Denver, CO 2019 [89]

Long-term goals:

- Develop and conduct new research studies (etiology and implementation science)

- Perform data modeling using new data obtained on natural history of EOCRC and risk factors to confirm and/or inform changes to current screening regimens (i.e., to begin at age 45)

- Impact change in large EMR systems to enhance adequate collection of family history data

- Facilitate development of national quality metrics for risk-based screening and management of young adults with symptoms 
- Increase adoption of universal tumor testing in health systems and community hospitals

\section{Limitations}

There are some limitations to this work. The speakers and attendees were selected to optimize input from individuals with diverse backgrounds, expertise and disciplines. However, there may have been groups and perspectives that were not adequately represented. The review of information and discussions to identify prominent themes for defining objectives and strategies was conducted by the authors and not vetted with all attendees.

\section{Conclusion}

Incidence of CRC among young adults has been on the rise for reasons largely unknown. Genetic predisposition and some established risk factors for CRC overall contribute to some EOCRC, though cannot explain the increase in risk in younger cohorts in recent decades. Further, there are gaps and challenges in clinical practice to identify persons at risk in order to mitigate disease occurrence and/or progression. New research and practice change are needed to illuminate causal factors and facilitate prevention and early detection of EOCRC to reduce morbidity and mortality from this emerging, and preventable disease.

\section{Future perspective}

This NCCRT Summit focused on the concerning and unexplained rise in EOCRC. Missed opportunities for prevention and early detection have resulted in significant years of life lost from a disease that is largely preventable. Efforts to mitigate the rising burden of EOCRC must include expanding our knowledge around its cause and natural history in order to identify opportunities for prevention and to inform policy around screening and clinical practice. We must also work to increase adoption of existing evidenced-based practices that we know work, but for which adherence is poor. An enduring status quo is unacceptable. Successful implementation of strategies identified herein to address these priority areas will require collaboration from multiple partners and a sincere commitment to collectively moving this work forward with a mission-oriented approach. We must keep the dialogue going and the work progressing to reduce the impact of a growing yet preventable burden of EOCRC.

\section{Summary points}

- There has been a significant rise in the incidence of colorectal cancer in younger adults and many are diagnosed at late stages.

- Common symptoms in young adults are similar to those in older adults, though often overlooked.

- Inherited mutations may explain $20 \%$ of colon cancers in younger adults; however, $80 \%$ are currently unexplained.

- Known environmental risk factors do not explain recent increase in young adults; research into role of novel risk factors specific to younger cohorts is needed.

- Practices should optimize collection of family history to identify those at risk, and improve recognition of symptoms in young adults.

- Commitment from diverse stakeholders are needed to increase awareness about the reality of colon cancer in young adults in the population and among healthcare providers.

Supplementary data

To view the supplementary data that accompany this paper please visit the journal website at: www.futuremedicine.com/doi/suppl/10.2217/crc-2020-0004

\section{Acknowledgments}

The authors acknowledge and thank the panel of invited speakers and attendees for their contributions to the Summit that provide the basis for this action plan (see Supplementary Appendix for meeting roster and meeting agenda), and to Richard Wender and TK Weber for chairing this event. The authors give a special thank you to Katie Couric and the National Colorectal Cancer Research Alliance for funding the commission of the meeting report and plan. They also thank Mary Doroshenk, former Director of the National Colorectal Cancer Roundtable, for contributions that cannot be quantified. They acknowledge her efforts in coordinating this meeting, conceptualizing this manuscript, securing its funding and for tirelessly leading and serving the organization for many years. 
The authors offer a special acknowledgement for TK Weber, who cochaired this Summit. TK Weber founded and served as president of the Colon Cancer Foundation, was past Chairman of the NCCRT, and established and chaired the Annual New York City Early Age Onset CRC Summit that seeks to increase awareness of early onset colorectal cancer and provide learning opportunities for clinicians, scientists and patients. TK Weber dedicated his professional life to reducing the threat and harm from colorectal cancer. TK Weber lost his own battle with cancer in the summer of 2019. His spirit, dedication to this cause and friendship will be greatly missed.

Financial \& competing interests disclosure

Funding for the summit and for this report was provided by American Cancer Society (ACS; contract 54016), the Colon Cancer Challenge Foundation, and the National Cancer Research Alliance, a fund of the Entertainment Industry Foundation. In addition, Speakers Bureau declares conflicts of interest with Ambry Genetics; Scientific Advisory Board, Cancer Prevention Pharmaceuticals. The authors have no other relevant affiliations or financial involvement with any organization or entity with a financial interest in or financial conflict with the subject matter or materials discussed in the manuscript apart from those disclosed.

No writing assistance was utilized in the production of this manuscript.

\section{Open access}

This work is licensed under the Creative Commons Attribution 4.0 License. To view a copy of this license, visit http://creativecomm ons.org/licenses/by/4.0/

\section{References}

1. Abdelsattar ZM, Wong SL, Regenbogen SE, Jomaa DM, Hardiman KM, Hendren S. Colorectal cancer outcomes and treatment patterns in patients too young for average-risk screening. Cancer 122(6), 929-934 (2016).

2. Siegel RL, Miller KD, Jemal A. Cancer statistics, 2018. CA Cancer J. Clin. 68(1), 7-30 (2018).

3. Siegel RL, Fedewa SA, Anderson WF et al. Colorectal cancer incidence patterns in the United States, 1974-2013. J. Natl Cancer Inst. 109(8), 2017).

4. Bailey CE, Hu CY, You YN et al. Increasing disparities in the age-related incidences of colon and rectal cancers in the United States, 1975-2010. JAMA Surg. 150(1), 17-22 (2015).

5. Wolf AMD, Fontham ETH, Church TR et al. Colorectal cancer screening for average-risk adults: 2018 guideline update from the American Cancer Society. CA Cancer J. Clin. 68(4), 250-281 (2018).

6. Khan SA, Morris M, Idrees $\mathrm{K}$ et al. Colorectal cancer in the very young: a comparative study of tumor markers, pathology and survival in early onset and adult onset patients. J. Pediatr. Surg. 51(11), 1812-1817 (2016).

7. You YN, Xing Y, Feig BW, Chang GJ, Cormier JN. Young-onset colorectal cancer: is it time to pay attention? Arch. Intern. Med. 172(3), 287-289 (2012).

8. Myers EA, Feingold DL, Forde KA, Arnell T, Jang JH, Whelan RL. Colorectal cancer in patients under 50 years of age: a retrospective analysis of two institutions' experience. World J. Gastroenterol. 19(34), 5651-5657 (2013).

9. Siminoff LA, Rogers HL, Harris-Haywood S. Missed opportunities for the diagnosis of colorectal cancer. Biomed. Res. Int. 2015,285096 (2015).

10. Fletcher RH, Lobb R, Bauer MR et al. Screening patients with a family history of colorectal cancer. J. Gen. Intern. Med. 22(4), 508-513 (2007).

11. Patel SG, Ahnen DJ, Kinney AY et al. Knowledge and uptake of genetic counseling and colonoscopic screening among individuals at increased risk for lynch syndrome and their endoscopists from the Family Health Promotion Project. Am. J. Gastroenterol. 111(2), 285-293 (2016).

12. Tsai MH, Xirasagar S, Li YJ, De Groen PC. Colonoscopy screening among US adults aged 40 or older with a family history of colorectal cancer. Prev. Chronic Dis. 12, E80 (2015).

13. Chen FW, Sundaram V, Chew TA, Ladabaum U. Advanced-stage colorectal cancer in persons younger than 50 years not associated with longer duration of symptoms or time to diagnosis. Clin. Gastroenterol. Hepatol. 15(5), 728-737.e723 (2017).

14. Siegel RL, Jakubowski CD, Fedewa SA, Davis A, Azad NS. Colorectal cancer in the young: epidemiology, prevention, management. Am. Soc. Clin. Oncol. Educ. Book 40, 1-14 (2020).

15. Araghi M, Soerjomataram I, Bardot A et al. Changes in colorectal cancer incidence in seven high-income countries: a population-based study. Lancet Gastroenterol. Hepatol. 4(7), 511-518 (2019).

16. Vuik FE, Nieuwenburg SA, Bardou M et al. Increasing incidence of colorectal cancer in young adults in Europe over the last 25 years. Gut 68(10), 1820-1826 (2019).

17. Young JP, Win AK, Rosty C et al. Rising incidence of early-onset colorectal cancer in Australia over two decades: report and review. J. Gastroenterol. Hepatol. 30(1), 6-13 (2015). 
18. Brenner DR, Ruan Y, Shaw E, De P, Heitman SJ, Hilsden RJ. Increasing colorectal cancer incidence trends among younger adults in Canada. Prev. Med. 105, 345-349 (2017).

19. Pearlman R, Frankel WL, Swanson B et al. Prevalence and spectrum of germline cancer susceptibility gene mutations among patients with early-onset colorectal cancer. JAMA Oncol. 3(4), 464-471 (2017).

20. Yurgelun MB, Allen B, Kaldate RR et al. Identification of a variety of mutations in cancer predisposition genes in patients with suspected lynch syndrome. Gastroenterology 149(3), 604-613.e620 (2015).

21. Stoffel EM, Koeppe E, Everett J et al. Germline genetic features of young individuals with colorectal cancer. Gastroenterology 154(4), 897-905.e891 (2018).

22. Mork ME, You YN, Ying J et al. High prevalence of hereditary cancer syndromes in adolescents and young adults with colorectal cancer. J. Clin. Oncol. 33(31), 3544-3549 (2015).

23. Lowery JT, Ahnen DJ, Schroy PC et al. Understanding the contribution of family history to colorectal cancer risk and its clinical implications: a state-of-the-science review. Cancer 122(17), 2633-2645 (2016).

24. Samadder NJ, Smith KR, Hanson $\mathrm{H}$ et al. Increased risk of colorectal cancer among family members of all ages, regardless of age of index case at diagnosis. Clin. Gastroenterol. Hepatol. 13(13), 2305.e2301-2311.2302 (2015).

25. Syed AR, Thakkar P, Horne ZD et al. Old vs. New: risk factors predicting early onset colorectal cancer. World. J. Gastrointest. Oncol. 11(11), 1011-1020 (2019).

26. Fuchs CS, Giovannucci EL, Colditz GA, Hunter DJ, Speizer FE, Willett WC. A prospective study of family history and the risk of colorectal cancer. N. Engl. J. Med. 331(25), 1669-1674 (1994).

27. Henrikson NB, Webber EM, Goddard KA et al. Family history and the natural history of colorectal cancer: systematic review. Genet. Med. 17(9), 702-712 (2015).

28. Lieberman DA, Weiss DG, Bond JH, Ahnen DJ, Garewal H, Chejfec G. Use of colonoscopy to screen asymptomatic adults for colorectal cancer. Veterans Affairs Cooperative Study Group 380. N. Engl. J. Med. 343(3), 162-168 (2000).

29. Van Duijnhoven FJ, Botma A, Winkels R, Nagengast FM, Vasen HF, Kampman E. Do lifestyle factors influence colorectal cancer risk in Lynch syndrome? Fam. Cancer 12(2), 285-293 (2013).

30. Fardet A, Druesne-Pecollo N, Touvier M, Latino-Martel P. Do alcoholic beverages, obesity and other nutritional factors modify the risk of familial colorectal cancer? A systematic review. Crit. Rev. Oncol. Hematol. 119, 94-112 (2017).

31. Movahedi M, Bishop DT, Macrae F et al. Obesity, aspirin, and risk of colorectal cancer in carriers of hereditary colorectal cancer: a prospective investigation in the CAPP2 Study. J. Clin. Oncol. 33(31), 3591-3597 (2015).

32. Miguchi M, Hinoi T, Tanakaya $\mathrm{K}$ et al. Alcohol consumption and early-onset risk of colorectal cancer in Japanese patients with Lynch syndrome: a cross-sectional study conducted by the Japanese Society for Cancer of the Colon and Rectum. Surg. Today 48(8), 810-814 (2018).

33. Rosato V, Bosetti C, Levi F et al. Risk factors for young-onset colorectal cancer. Cancer Causes Control 24(2), 335-341 (2013).

34. Doubeni CA, Major JM, Laiyemo AO et al. Contribution of behavioral risk factors and obesity to socioeconomic differences in colorectal cancer incidence. J. Natl Cancer Inst. 104(18), 1353-1362 (2012).

35. Huxley RR, Ansary-Moghaddam A, Clifton P, Czernichow S, Parr CL, Woodward M. The impact of dietary and lifestyle risk factors on risk of colorectal cancer: a quantitative overview of the epidemiological evidence. Int. J. Cancer 125(1), 171-180 (2009).

36. Vieira AR, Abar L, Chan DSM et al. Foods and beverages and colorectal cancer risk: a systematic review and meta-analysis of cohort studies, an update of the evidence of the WCRF-AICR Continuous Update Project. Ann. Oncol. 28(8), 1788-1802 (2017).

37. Platz EA, Willett WC, Colditz GA, Rimm EB, Spiegelman D, Giovannucci E. Proportion of colon cancer risk that might be preventable in a cohort of middle-aged US men. Cancer Causes Control 11(7), 579-588 (2000).

38. Liu PH, Wu K, Ng K et al. Association of obesity with risk of early-onset colorectal cancer among women. JAMA Oncol. 5(1), 37-44 (2018).

39. Menke A, Casagrande S, Geiss L, Cowie CC. Prevalence of and trends in diabetes among adults in the United States, 1988-2012. JAMA 314(10), 1021-1029 (2015).

40. Wang TW, Asman K, Gentzke AS et al. Tobacco product use among adults - United States, 2017. MMWR Morb. Mortal. Wkly Rep. 67(44), 1225-1232 (2018).

41. Grucza RA, Sher KJ, Kerr WC et al. Trends in adult alcohol use and binge drinking in the early 21 st-century United States: a meta-analysis of 6 national survey series. Alcohol. Clin. Exp. Res. 42(10), 1939-1950 (2018).

42. Daniel CR, Cross AJ, Koebnick C, Sinha R. Trends in meat consumption in the USA. Public Health Nutr. 14(4), 575-583 (2011).

43. Hales CM, Fryar CD, Carroll MD, Freedman DS, Ogden CL. Trends in obesity and severe obesity prevalence in US youth and adults by sex and age, 2007-2008 to 2015-2016. JAMA 319(16), 1723-1725 (2018).

44. Carlson SA, Fulton JE, Schoenborn CA, Loustalot F. Trend and prevalence estimates based on the 2008 Physical Activity Guidelines for Americans. Am. J. Prev. Med. 39(4), 305-313 (2010). 
45. Rothwell PM, Wilson M, Elwin CE et al. Long-term effect of aspirin on colorectal cancer incidence and mortality: 20-year follow-up of five randomised trials. Lancet 376(9754), 1741-1750 (2010).

46. Gu Q, Dillon CF, Eberhardt MS, Wright JD, Burt VL. Preventive aspirin and other antiplatelet medication use among U.S. adults aged $>$ /= 40 years: data from the National Health and Nutrition Examination Survey, 2011-2012. Public Health Rep. 130(6), 643-654 (2015).

47. Cea Soriano L, Soriano-Gabarro M, Garcia Rodriguez LA. The protective effect of low-dose aspirin against colorectal cancer is unlikely explained by selection bias: results from three different study designs in clinical practice. PLoS ONE 11(7), e0159179 (2016).

48. Chapman J, Bhimji SS. Reye Syndrome. In: StatPearls. StatPearls Publishing LLC, FL, USA (2018).

49. Ng SC, Shi HY, Hamidi N et al. Worldwide incidence and prevalence of inflammatory bowel disease in the 21 st century: a systematic review of population-based studies. Lancet 390(10114), 2769-2778 (2018).

50. Lakatos PL, Lakatos L. Risk for colorectal cancer in ulcerative colitis: changes, causes and management strategies. World J. Gastroenterol. 14(25), 3937-3947 (2008).

51. Murphy CC, Lund JL, Sandler RS. Young-onset colorectal cancer: earlier diagnoses or increasing disease burden? Gastroenterology 152(8), 1809-1812.e1803 (2017).

52. Fedewa SA, Siegel RL, Jemal A. Are temporal trends in colonoscopy among young adults concordant with colorectal cancer incidence?. J. Med. Screen. 26(4), 179-185 (2019).

53. Gryfe R, Kim H, Hsieh ET et al. Tumor microsatellite instability and clinical outcome in young patients with colorectal cancer. N. Engl. J. Med. 342(2), 69-77 (2000).

54. Losi L, Di Gregorio C, Pedroni M et al. Molecular genetic alterations and clinical features in early-onset colorectal carcinomas and their role for the recognition of hereditary cancer syndromes. Am. J. Gastroenterol. 100(10), 2280-2287 (2005).

55. Goel A, Nagasaka T, Spiegel J, Meyer R, Lichliter WE, Boland CR. Low frequency of Lynch syndrome among young patients with non-familial colorectal cancer. Clin. Gastroenterol. Hepatol. 8(11), 966-971 (2010).

56. Giraldez MD, Balaguer F, Bujanda $\mathrm{L}$ et al. MSH6 and MUTYH deficiency is a frequent event in early-onset colorectal cancer. Clin. Cancer Res. 16(22), 5402-5413 (2010).

57. Ballester V, Rashtak S, Boardman L. Clinical and molecular features of young-onset colorectal cancer. World J. Gastroenterol. 22(5), 1736-1744 (2016).

58. Xicola RM, Manojlovic Z, Augustus GJ et al. Lack of APC somatic mutation is associated with early-onset colorectal cancer in African Americans. Carcinogenesis 39(11), 1331-1341 (2018).

59. Willauer AN, Liu Y, Pereira AaL et al. Clinical and molecular characterization of early-onset colorectal cancer. Cancer 125(12), 2002-2010 (2019).

60. Antelo M, Balaguer F, Shia J et al. A high degree of LINE-1 hypomethylation is a unique feature of early-onset colorectal cancer. PLoS ONE 7(9), e45357 (2012).

61. Hur K, Cejas P, Feliu J et al. Hypomethylation of long interspersed nuclear element-1 (LINE-1) leads to activation of proto-oncogenes in human colorectal cancer metastasis. Gut 63(4), 635-646 (2014).

62. Crujeiras AB, Morcillo S, Diaz-Lagares A et al. Identification of an episignature of human colorectal cancer associated with obesity by genome-wide DNA methylation analysis. Int. J. Obes. 43(1), 176-188 (2019).

63. Clinical Practice Guidelines for Oncology. Colorectal Cancer Screening, V 1.2015. (2015). www.nccn.org/professionals/physician_gls/pdf/colorectal_screening.pdf

64. Rex DK, Boland CR, Dominitz JA et al. Colorectal cancer screening: recommendations for physicians and patients from the U.S. multi-society task force on colorectal cancer. Am. J. Gastroenterol. 112(7), 1016-1030 (2017).

65. Hampel H, De La Chapelle A. The search for unaffected individuals with Lynch syndrome: do the ends justify the means? Cancer Prev. Res. (Phila.) 4(1), 1-5 (2011).

66. Wideroff L, Freedman AN, Olson L et al. Physician use of genetic testing for cancer susceptibility: results of a national survey. Cancer Epidemiol. Biomarkers Prev. 12(4), 295-303 (2003).

67. Foo W, Young JM, Solomon MJ, Wright CM. Family history? The forgotten question in high-risk colorectal cancer patients. Colorectal Dis. 11(5), 450-455 (2009).

68. Weingart SN, Stoffel EM, Chung DC et al. Working up rectal bleeding in adult primary care practices. J. Eval. Clin. Pract. 23(2), 279-287 (2017).

69. Powell KP, Christianson CA, Hahn SE et al. Collection of family health history for assessment of chronic disease risk in primary care. $N$. C. Med. J. 74(4), 279-286 (2013).

70. Evaluation of Genomic Applications in Practice and Prevention (EGAPP) Working Group. Recommendations from the EGAPP Working Group: genetic testing strategies in newly diagnosed individuals with colorectal cancer aimed at reducing morbidity and mortality from Lynch syndrome in relatives. Genet. Med. 11(1), 35-41 (2009). 
71. Beamer LC, Grant ML, Espenschied CR et al. Reflex immunohistochemistry and microsatellite instability testing of colorectal tumors for Lynch syndrome among US cancer programs and follow-up of abnormal results. J. Clin. Oncol. 30(10), 1058-1063 (2012).

72. National Cancer Database. www.facs.org/-/media/files/quality-programs/cancer/ncdb/ncdb_2016_booklet_v11.ashx?la=en

73. NCI-Designated Cancer Centers. www.cancer.gov/research/nci-role/cancer-centers

74. Shaikh T, Handorf EA, Meyer JE, Hall MJ, Esnaola NF. Mismatch repair deficiency testing in patients with colorectal cancer and nonadherence to testing guidelines in young adults. JAMA Oncol. 4(2), e173580 (2018).

75. Karlitz JJ, Hsieh MC, Liu Y et al. Population-based lynch syndrome screening by microsatellite instability in patients $</=50$ : prevalence, testing determinants, and result availability prior to colon surgery. Am. J. Gastroenterol. 110(7), 948-955 (2015).

76. Noll A, Parekh PJ, Zhou M et al. Barriers to lynch syndrome testing and preoperative result availability in early-onset colorectal cancer: a national physician survey study. Clin. Transl. Gastroenterol. 9(9), 185 (2018).

77. Ait Ouakrim D, Lockett T, Boussioutas A, Hopper JL, Jenkins MA. Screening participation for people at increased risk of colorectal cancer due to family history: a systematic review and meta-analysis. Fam. Cancer 12(3), 459-472 (2013).

78. Rees G, Martin PR, Macrae FA. Screening participation in individuals with a family history of colorectal cancer: a review. Eur. J. Cancer Care (Engl.) 17(3), 221-232 (2008).

79. Ait Ouakrim D, Lockett T, Boussioutas A et al. Screening participation predictors for people at familial risk of colorectal cancer: a systematic review. Am. J. Prev. Med. 44(5), 496-506 (2013).

80. Ingrand I, Dujoncquoy S, Beauchant M, Letard JC, Migeot V, Ingrand P. General practitioner and specialist views on colonoscopic screening of first-degree relatives of colorectal cancer patients. Cancer Epidemiol. 33(3-4), 223-230 (2009).

81. Peterse EFP, Meester RGS, Siegel RL et al. The impact of the rising colorectal cancer incidence in young adults on the optimal age to start screening: microsimulation analysis I to inform the American Cancer Society colorectal cancer screening guideline. Cancer 124(14), 2964-2973 (2018).

82. Scott RB, Rangel LE, Osler TM, Hyman NH. Rectal cancer in patients under the age of 50 years: the delayed diagnosis. Am. J. Surg. 211(6), 1014-1018 (2016).

83. De Jong AE, Vasen HF. The frequency of a positive family history for colorectal cancer: a population-based study in the Netherlands. Neth. J. Med. 64(10), 367-370 (2006).

84. Van Hout AM, De Wit NJ, Rutten FH, Peeters PH. Determinants of patient's and doctor's delay in diagnosis and treatment of colorectal cancer. Eur. J. Gastroenterol. Hepatol. 23(11), 1056-1063 (2011).

85. Greene MA, Butterly LF, Goodrich M et al. Matching colonoscopy and pathology data in population-based registries: development of a novel algorithm and the initial experience of the New Hampshire Colonoscopy Registry. Gastrointest. Endosc. 74(2), 334-340 (2011).

86. Kulchak Rahm A, Cragun D, Hunter J et al. Implementing universal Lynch syndrome screening (IMPULSS): protocol for a multi-site study to identify strategies to implement, adapt, and sustain genomic medicine programs in different organizational contexts. $B M C$ Health Serv. Res. 18(824), doi:10.1186/s12913-018-3636-2 (2018).

87. Trivers KF, Rodriguez JL, Cox SL, Crane BE, Duquette D. The activities and impact of state programs to address hereditary breast and ovarian cancer, 2011-2014. Healthcare (Basel, Switzerland) 3(4), 948-963 (2015).

88. National Colorectal Cancer Roundtable. 2019 colorectal cancer screening messaging guidebook: recommended messages to reach the unscreened. https://nccrt.org/resource/2019messagingguidebook/

89. Dwyer AJ, Murphy CC, Boland CR et al. A summary of the fight colorectal cancer working meeting: exploring risk factors and etiology of sporadic early-age onset colorectal cancer. Gastroenterology 157(2), 280-288 (2019).

90. Advanced Colorectal Polyp Brief. https://nccrt.org/resource/advanced-colorectal-polyp-brief/

91. Molmenti CL, Kolb JM, Karlitz JJ. Advanced colorectal polyps on colonoscopy: a trigger for earlier screening of family members. Am. J. Gastroenterol. 115(3), 311-314 (2020). 